\title{
Ontogeny of Surfactant Apoproteins in the Rat
}

\author{
DENNIS E. SCHELlHASE, PHILIP A. EMRIE, JAMES H. FISHER, AND JOHN M. SHANNON \\ Department of Pediatrics, University of Colorado Health Sciences Center, Denver, Colorado 80262 [D.E.S.]; \\ Department of Medicine, National Jewish Center for Immunology and Respiratory Medicine; Denver, Colorado \\ 80206 [P.A.E. J.M.S.]; and Department of Medicine, University of Colorado Health Sciences Center, Denver, \\ Colorado 80262 [J.H.F.]
}

\begin{abstract}
Content of the 26-38-kD surfactant apoprotein (SP-A) was determined in lung homogenates from fetal (17-21 d gestation), postnatal (1-28 d of life), and adult male and female rats by a double sandwich ELISA. Expression of mRNA for SP-A as well as the hydrophobic apoproteins, SP-B and SP-C, were also determined in lung homogenates from fetal and adult rats of both sexes by Northern blot analysis. SP-A was undetectable in fetal lungs on $d 17$ (day of birth $=\mathrm{d} 22$ ) and barely detectable on d 18. On d 19 there was a 3- to 4-fold increase in SPA content above d 18 levels. Between d 19 and 21 SP-A content significantly increased another 6- to 9-fold. SP-A content on the day of birth was not significantly different from that seen on gestational d 21. SP-A content decreased $35-40 \%$ between the day of birth and postnatal d 7 . After the second postnatal week SP-A content gradually increased, reaching adult levels after $\mathrm{d} 28$. No sex differences in SP-A content were observed during fetal or postnatal lung maturation. SP-A mRNA was first detected in fetal lungs on $\mathbf{d} 18$ and increased in relative abundance until d 21, but remained below adult levels. Developmental changes in fetal lung SP-A content closely paralleled changes in fetal expression of SP-A mRNA. SP-B mRNA was also first detected on $\mathrm{d} 18$, then increased in relative abundance to adult levels by d 20. SP-C mRNA was clearly detectable on $\mathrm{d} 17$, then increased in relative abundance to adult levels by d 20-21. Unlike surfactant phospholipids, there are no apparent sex differences in the expression of any of the surfactant apoproteins during late gestation. The differences observed during fetal lung maturation in the time of onset and changes in relative abundance among the three apoprotein mRNA imply that their genes may be differentially regulated in the developing rat lung. (Pediatr Res 26:167-174, 1989)
\end{abstract}

\section{Abbreviations}

SP-A, lung-specific surfactant apoprotein of mol wt 26-38 kD (reduced)

SP-B, hydrophobic lung-specific surfactant apoprotein of mol wt $7 \mathrm{kD}$ (reduced)

SP-C, hydrophobic lung-specific surfactant apoprotein of mol wt $5 \mathrm{kD}$ (reduced)

Received December 12, 1988; accepted May 8, 1989.

Correspondence Dennis E. Schellhase, M.D., Pediatric Pulmonary Fellow, University of Colorado Health Sciences Center, Pediatric Pulmonary Division, 4200 E. 9th Street Box C-220, Denver, CO 80262.

Reprint requests John M. Shannon, Ph.D., National Jewish Center for Immunology and Respiratory Medicine, 1400 Jackson Street K625, Denver, CO 80206.

Supported by Cystic Fibrosis Foundation Grant D0209-01 (Fellowship Grant Award to D.E.S.); NIH Grant HL 02181 (P.A.E.); and Biomedical Research Support Grant PHS RR05842 (J.M.S.).
Pulmonary surfactant is a complex aggregation of phospholipids and lung-specific apoproteins that functions to reduce surface tension in the alveolus and maintain alveolar stability at low lung volumes $(1,2)$. Surfactant is composed of $80-90 \%$ phospholipids, $10 \%$ cholesterol, and $5-10 \%$ protein. The major functional component of surfactant phospholipids appears to be dipalmitoyl phosphatidylcholine (3). Three families of lung-specific apoproteins have been described (4). The most well characterized of these is a glycoprotein with a $\mathrm{M}_{\mathrm{r}}$ of $26-38 \mathrm{kD}$ under reducing conditions (5) that has recently been designated SP-A (4). SP-A has been shown to play a role in the formation of tubular myelin in the presence of calcium ions (6) and in enhancing the adsorption of surface-active phospholipids to an air-liquid interface (7). SP-A has also been shown to inhibit secretion of phosphatidylcholine in cultured adult rat alveolar type II cells and thus may be important in the regulation of surfactant secretion $(8-10)$. Two other very hydrophobic proteins are specifically associated with surfactant and have been designated SP-B and SP-C (4). SP-B has a $M_{r}$ of $18 \mathrm{kD}$ under nonreducing conditions and a $\mathrm{M}_{\mathrm{r}}$ of 5-8 $\mathrm{kD}$ under reducing conditions (5). SP-B is capable of enhancing the adsorption of surface-active phospholipids at an air-liquid interface in the presence of calcium ions. When combined with SP-A, this effect is further enhanced (11), SP-C has a $M_{r}$ of $5-8 \mathrm{kD}$ under both reducing and nonreducing conditions (5). SP-C may also play a role in enhancing adsorption of surface-active phospholipids at an air-liquid interface; however, its major functions remain to be defined.

There is a marked increase in lung synthesis and content of surfactant phospholipids in most mammals at the completion of 85 to $90 \%$ of gestation (12). Sex differences exist in the appearance of surfactant phospholipids in human amniotic fluid (13) and in fetal rat lung (14). Recently, SP-A has been shown to markedly increase in human amniotic fluid (15) and in fetal rat lung (16) during the latter part of gestation. No information is available, however, concerning sex differences in the appearance of SP-A and SP-A mRNA in the fetal lung. Recently, in vitro translatable SP-A mRNA has been shown to decline in rabbit neonatal and adult lung $(17,18)$ and SP-A content has been shown to decline in neonatal rat lung (19). However, no information is available concerning postnatal changes in lung SP-A content after the immediate neonatal period. Little information is available concerning appearance of SP-B and SP-C in the fetal lung; accordingly, no information exists regarding possible sex differences in expression of these hydrophobic apoproteins. In this report, we describe the ontogeny of SP-A in the fetal and postnatal male and female rat lung and the expression of mRNA's for SP-A, SP-B, and SP-C in the fetal male and female rat lung.

\section{MATERIALS AND METHODS}

Animals. Time-dated pregnant Sprague-Dawley rats were obtained from Sasco, Inc. (Omaha, NE) and Bantin and Kingman, 
Inc. (Fremont, CA). Gestational age was initially determined with the day of sperm positive vaginal smear as $\mathrm{d} 0$ (d of birth $=$ $\mathrm{d} 22$ ). Because of occasional wide variation of mean fetal weight in different litters of purportedly the same gestational age, we also standardized gestational age on the basis of mean fetal weight (Table 1) (16).

Fetal rats were delivered by rapid postmortem hysterotomy; fetal and postnatal rats less than $7 \mathrm{~d}$ of age were sacrificed by decapitation. Postnatal rats older than $7 \mathrm{~d}$ of age and pregnant female rats were killed by intraperitoneal injections of pentobarbital and transection of the abdominal aorta. Fetal and neonatal sex were determined by direct gonadal examination with a dissecting microscope.

Preparation of lung tissue. Lung tissue was rapidly removed from the chest cavity and placed in PBS on ice. Male and female fetal lungs were pooled separately for each litter. Samples for SP-A, DNA, and protein content were rapidly frozen in a dry ice/alcohol bath and stored at $-70^{\circ} \mathrm{C}$ until assay. Samples for RNA and electron microscopy were briefly placed in PBS on ice and then prepared as described below.

Determination of lung SP-A content. Lung SP-A content was determined by a double sandwich ELISA using a polyclonal antibody raised against rat SP-A. The assay is capable of accurately measuring SP-A in concentrations of $1-20 \mathrm{ng} / \mathrm{mL}$. Standard curves obtained in this range had linear regression coefficients of 0.999 . Rat SP-A was purified from bronchoalveolar lavage fluid from adult rats that had been instilled with silica to increase the yield of SP-A (10). Purified SP-A was emulsified in Freund's complete adjuvant and injected into a New Zealand rabbit (Hazleton Research Products, Denver, PA). Then 2 and $6 \mathrm{wk}$ after the initial immunization, SP-A emulsified in Freund's incomplete adjuvant was injected into the same New Zealand rabbit. The IgG fraction from immunized rabbit serum was purified by chromatography on a Protein-A Sepharose 6B column (Pharmacia LKB Biotechnology, Inc., Piscataway, NJ) followed by Affi-Gel 10 and 15 columns (BioRad, Richmond, CA) conjugated with rat serum. That the rabbit polyclonal antirat SP-A IgG antibodies only recognized rat SP-A was confirmed by immunoblot analysis (data not shown); further, SP-A was not detected in fetal or postnatal rat liver or kidney. Thus, the ELISA is both sensitive and specific for rat lung SP-A.

For the ELISA, $0.1 \mathrm{~mL}$ rabbit antirat SP-A IgG fraction $(0.1$ $\mu \mathrm{g} / \mathrm{mL}$ in $0.1 \mathrm{M} \mathrm{NaHCO} 3, \mathrm{pH} 9.3$ ) was incubated overnight at $22^{\circ} \mathrm{C}$ in wells of untreated microtiter plates (Dynatech Laboratories Inc., Alexandria, VA). The wells were then allowed to incubate at least $30 \mathrm{~min}$ with PBS without calcium or magnesium, pH 7.4 containing $1 \%$ (vol/vol) Triton X-100 (Sigma

Table 1. Animal $w$ t for various ages studied*

\begin{tabular}{|c|c|c|}
\hline & \multicolumn{2}{|c|}{ Body wt $(\mathrm{g})^{*}$} \\
\hline & Male & Female \\
\hline \multicolumn{3}{|l|}{ Fetal } \\
\hline $17 \mathrm{~d}$ & $0.81 \pm 0.06(9)$ & $0.70 \pm 0.07(13)$ \\
\hline $18 \mathrm{~d}$ & $1.48 \pm 0.11(13)$ & $1.41 \pm 0.11(9)$ \\
\hline $19 \mathrm{~d}$ & $2.44 \pm 0.20(16)$ & $2.43 \pm 0.27(6)$ \\
\hline $20 \mathrm{~d}$ & $4.32 \pm 0.31(4)$ & $4.19 \pm 0.16(4)$ \\
\hline $21 \mathrm{~d}$ & $5.82 \pm 0.36(6)$ & $5.90 \pm 0.18(5)$ \\
\hline \multicolumn{3}{|l|}{ Postnatal } \\
\hline $1 \mathrm{~d}$ & $6.45 \pm 0.74(5)$ & $5.94 \pm 0.43(5)$ \\
\hline $2 \mathrm{~d}$ & $8.04 \pm 0.15(6)$ & $7.76 \pm 1.04(6)$ \\
\hline $5 d$ & $11.22 \pm 2.47(6)$ & $10.08 \pm 1.75(6)$ \\
\hline $7 \mathrm{~d}$ & $14.42 \pm 0.76(7)$ & $12.65 \pm 1.98(5)$ \\
\hline $14 \mathrm{~d}$ & $33.76 \pm 1.54(6)$ & $26.82 \pm 1.56(6)$ \\
\hline $28 \mathrm{~d}$ & $78.77 \pm 10.53(6)$ & $79.58 \pm 3.30(6)$ \\
\hline Adult & $200-250(4)$ & $200-250(4)$ \\
\hline
\end{tabular}

\footnotetext{
* Values are expressed as mean \pm SD of the number of animals given
} in parentheses.
Chemical Co., St. Louis, MO) and 3\% (w/v) BSA (Sigma) (3\% $\mathrm{BSA} / 1 \%$ Triton $\mathrm{X}-100 / \mathrm{PBS})$. The wells were washed twice with $1 \%$ Triton $\mathrm{X}-100 / \mathrm{PBS}$, then $0.1 \mathrm{~mL}$ of purified rat SP-A standard $(0-20 \mathrm{ng} / \mathrm{mL}$ in $5 \mathrm{mM}$ Tris buffer) or various dilutions of sample lung homogenate were added to each well and allowed to incubate at $37^{\circ} \mathrm{C}$ for $90 \mathrm{~min}$. The wells were washed three times with $3 \% \mathrm{BSA} / 1 \%$ Triton $\mathrm{X}-100 / \mathrm{PBS}$, then $0.1 \mathrm{~mL}$ of rabbit anti-rat SP-A IgG fraction $(20 \mu \mathrm{g} / \mathrm{mL}$ in $3 \%$ BSA $/ 1 \%$ Triton $X-100 /$ PBS) conjugated with horseradish peroxidase (Boehringer Mannheim, Indianapolis, IN) was added to each well and allowed to incubate at $37^{\circ} \mathrm{C}$ for $90 \mathrm{~min}$. After four washes with $1 \%$ Triton X-100/PBS, $0.1 \mathrm{~mL}$ of substrate solution $[0.1 \%$ (wt/vol) $0-$ phenylenediamine (Sigma), $0.03 \%$ (vol/vol) hydrogen peroxide (Fisher Scientific Co., Pittsburgh PA), 0.1 M citrate buffer, pH 4.6] was added to each well and allowed to incubate at $22^{\circ} \mathrm{C}$ in the dark for $15 \mathrm{~min}$. The reaction was stopped by the addition of $0.1 \mathrm{~mL}$ of $2 \mathrm{M}$ sulfuric acid per well. The absorbance at OD $490 \mathrm{~nm}$ was determined with a Microplate Autoreader EL 309 (BioTek Instruments Inc., VT).

Determination of lung DNA. Lung tissue $(20-50 \mathrm{mg})$ was homogenized in $4 \mathrm{~mL}$ of $1 \%$ Triton X-100/PBS using a Polytron (Brinkman Instruments, Westbury, NY). DNA was prepared from $0.1-0.2 \mathrm{ml}$ of the lung homogenate by precipitation with $10 \%$ trichloracetic acid and extraction with methanol and absolute alcohol. DNA was then assayed by the fluorometric method of Setaro and Morley (20).

Determination of lung protein. Lung tissue was homogenized in $1 \%$ Triton $\mathrm{X}-100 / \mathrm{PBS}$ as described above. Protein content was then determined from $0.025-0.050 \mathrm{~mL}$ of lung homogenate by the bicinchoninic acid method of Smith et al. (21).

Preparation of RNA and Northern blot analysis. Total RNA was extracted from lung tissue with $4 \mathrm{M}$ guanidinium isothiocyanate, $0.5 \%$ N-laurylsarcosine, and $0.1 \mathrm{M} \beta$-mercaptoethanol in $25 \mathrm{mM}$ sodium citrate buffer. The RNA was purified by centrifuging the lysate through a cushion of $5.7 \mathrm{M} \mathrm{CsCl}$ at $150000 \times g$ for $18 \mathrm{~h}$ at $22^{\circ} \mathrm{C}(22)$. RNA was then size-fractionated by electrophoresis through a $1.0 \%$ agarose gel under denaturing conditions and transferred to nitrocellulose or Nytran (both from Schleicher \& Schuell, Keene, $\mathrm{NH}$ ) by capillary action. Northern blots were prehybridized at $42^{\circ} \mathrm{C}$ for $2 \mathrm{~h}$ in $5 \times$ SSPE $(1 \times$ SSPE is $0.15 \mathrm{M}$ sodium chloride, $10 \mathrm{mM}$ sodium phosphate, and 1 mM EDTA, pH 7.0), 0.1\% SDS, $5 \times$ Denhardt's solution, 0.2 $\mathrm{mg} / \mathrm{ml}$ salmon sperm DNA (Sigma), 50\% formamide (International Biotechnologies Inc., New Haven, CT) and then hybridized with $5 \times 10^{5} \mathrm{dpm} / \mathrm{ml}{ }^{32} \mathrm{P}$-labeled specific rat cDNA probe in $5 \times$ SSPE, $5 \times$ Denhardt's solution, $0.2 \mathrm{mg} / \mathrm{ml}$ salmon sperm DNA, $10 \%$ dextran sulfate, $0.1 \%$ SDS, and $50 \%$ formamide at $42^{\circ} \mathrm{C}$ for $16-24 \mathrm{~h} .{ }^{32} \mathrm{P}-$-labeled SP-A CDNA was prepared by random primer second strand synthesis (25) from a previously isolated rat cDNA for SP-A (23). Rat SP-B CDNA was isolated from a rat lung $\lambda \mathrm{gt}^{10} \mathrm{cDNA}$ library (kindly provided by Dr. F. Murad, Stanford University, Stanford, CA) by screening with a human SP-B cDNA clone (kindly provided by Dr. R. T. White, California Biotech Inc., Mountain View, CA) (24). ${ }^{32}$ P-labeled SP-B cDNA was prepared from purified rat SP-B insert isolated on a low temperature melting agarose gel and labeled by random primer second strand synthesis (25). Rat SP-C cDNA was isolated from the same rat lung cDNA library using a human SP-C cDNA clone (kindly provided by Dr. R. T. White) (26). ${ }^{32} \mathrm{P}$-labeled SP$\mathrm{C}$ cDNA was prepared from rat SP-C insert isolated on a low temperature melting agarose gel and labeled by random primer second strand synthesis (25). Given the fact that all three inserts are of similar length and GC content, are of rat origin, and are radiolabeled by the same technique, then the efficiency of hybridization of all three probes should be nearly identical. After hybridization, Northern blots were washed four times for $30 \mathrm{~min}$ at $42^{\circ} \mathrm{C}$ in $400-\mathrm{ml}$ portions of $2 \times \mathrm{SSC}(1 \times \mathrm{SSC}$ is $0.15 \mathrm{M}$ sodium chloride and $15 \mathrm{mM}$ trisodium citrate) plus $0.1 \%$ SDS, followed by one 30 -min wash at $55^{\circ} \mathrm{C}$ in $0.2 \times$ SSC plus $0.1 \%$ SDS, and then a final wash for $5 \mathrm{~min}$ at $55^{\circ} \mathrm{C}$ in $0.2 \times \mathrm{SSC}$. Northern blots 
were autoradiographed at $-70^{\circ} \mathrm{C}$ using Kodak X-Omatic cassettes equipped with intensifying screens (Eastman Kodak, Rochester, NY). For reprobing, blots were heated to $85^{\circ} \mathrm{C}$ in $1 \%$ glycerol in water for $10 \mathrm{~min}$ (27) and then hybridized with another ${ }^{32} \mathrm{P}$-labeled specific probe under the hybridization conditions described above. Efficient removal of radiolabeled probe was monitored by autoradiography of washed blots for $24 \mathrm{~h}$ at $-70^{\circ} \mathrm{C}$.

Electron microscopy. Fetal rat lung samples were prepared for transmission electron microscopic examination as previously described (28). Briefly, fetal rat lung tissue was immersed in fixative containing $2 \%$ glutaraldehyde, $1 \%$ paraformaldehyde, in a $0.1 \mathrm{M}$ phosphate buffer. After $4 \mathrm{~h}$ tissue samples were transferred to a $1.5 \%$ osmium tetroxide in veronal acetate buffer and postfixed overnight. Specimens were then en bloc stained with $1.5 \%$ uranyl acetate in sodium maleate buffer, rapidly dehydrated with a graded series of acetone, transferred to propylene oxide, then infiltrated and embedded in a Luft's 3:7 epon resin (29). Sections were stained with uranyl acetate and lead citrate (30), and then examined in a Philips 400T electron microscope.

Statistics. Determinations of fetal lung SP-A, DNA, and protein content were performed on three to five litters per age for gestational ages 17-21 d. Male and female fetal lungs were pooled separately for each litter as described above. Determinations of postnatal and adult lung SP-A, DNA, and protein content were performed on four to seven animals per age. Values for lung SP-A content are expressed as mean (ng SP-A/ $\mu$ g DNA or pg $\mathrm{SP}-\mathrm{A} / \mu \mathrm{g}$ protein) $\pm \mathrm{SE}$. Differences in SP-A content at different ages and sex differences in SP-A content at each age were compared by ANOVA. Inasmuch as there were only significant differences in SP-A content on the basis of age $(p<0.001)$, differences in SP-A content at different ages were further analyzed by Ryan-Einot-Gabriel-Welsch multiple range test (31) with statistical significance accepted at $p<0.05$. Statistical analyses were run on SAS software (SAS Institute Inc. Cary, NC).

\section{RESULTS}

Electron microscopy. The ultrastructural appearance of fetal lungs analyzed in this study was consistent with that described previously (32). On gestational d 17 (glandular stage), the respiratory epithelium was characterized by undifferentiated tall columnar epithelial cells, some of which contained small accumulations of intracellular glycogen. There were no identifiable lamellar bodies (Fig. 1). On gestational d 19 (canalicular stage), the respiratory epithelium was characterized by more cuboidalshaped epithelial cells, some of which now demonstrated morphological characteristics of type II cells (Fig. 2). These early type II cells contained lamellar bodies and large accumulations of intracellular glycogen. Occasional lamellar whorls could be found in airway lumina. On gestational d 21 (terminal sac stage), the respiratory epithelium was characterized by a more flattened appearance with mature type II cells, type I cells, occasional undifferentiated cells, and close approximation to the capillary endothelium (Fig. 3). These type II cells contained lamellar bodies and only small or nonexistent intracellular accumulations of glycogen. Lamellar whorls and tubular myelin could be found in airway lumina. Although quantitative morphometric analysis was not performed, there were no grossly apparent morphological sex differences noted on gestational d 17,19 , or 21 .

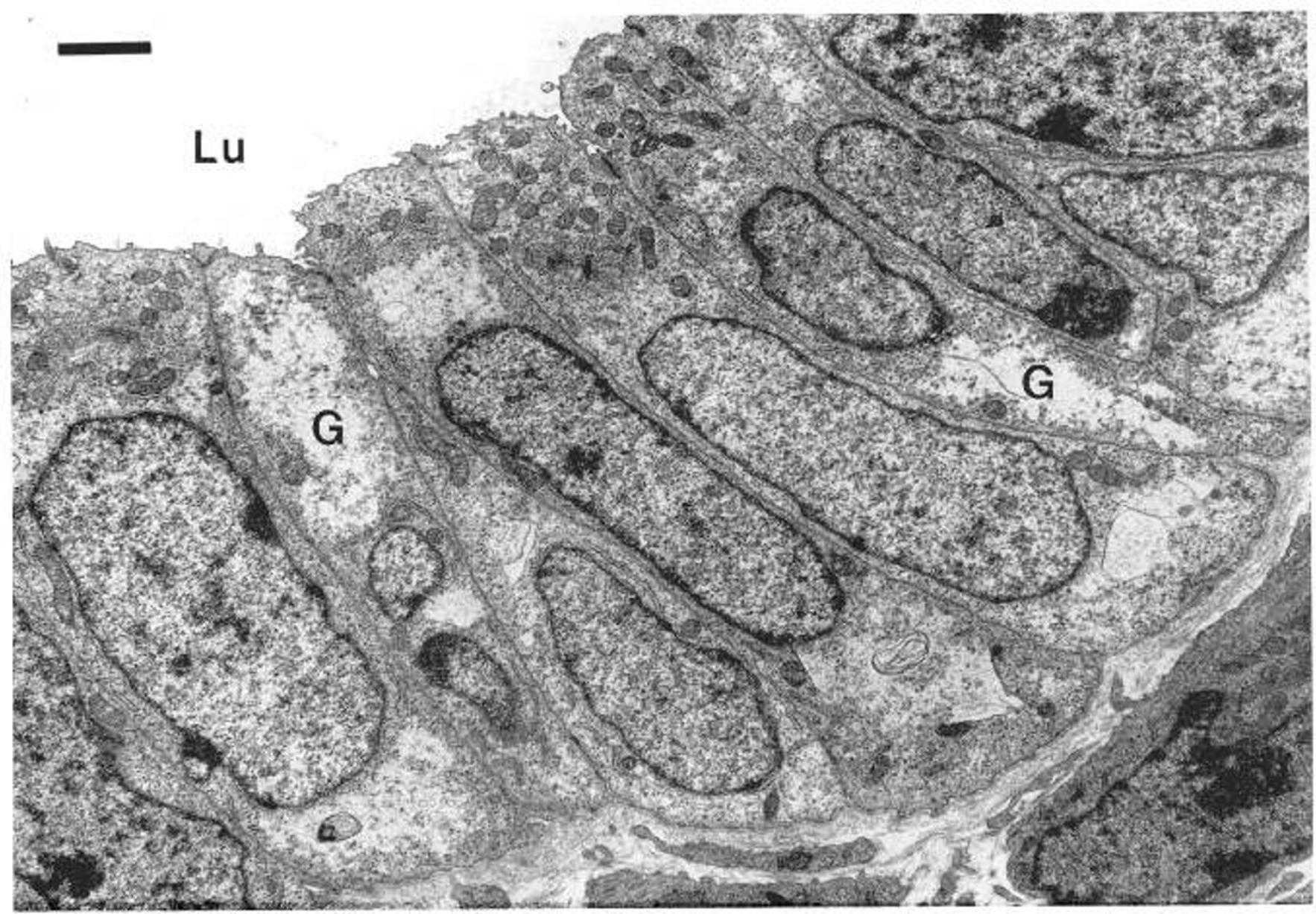

Fig. 1. Electron micrograph of respiratory epithelium from gestational day 17 ( $b a r, 2.0 \mu \mathrm{m}$; $L u$, airway lumen). Note undifferentiated tall columnar epithelial cells, some of which contain small intracellular accumulations of glycogen $(G)$. There are no identifiable type II cells. These characteristics are typical of the glandular stage of lung development. 


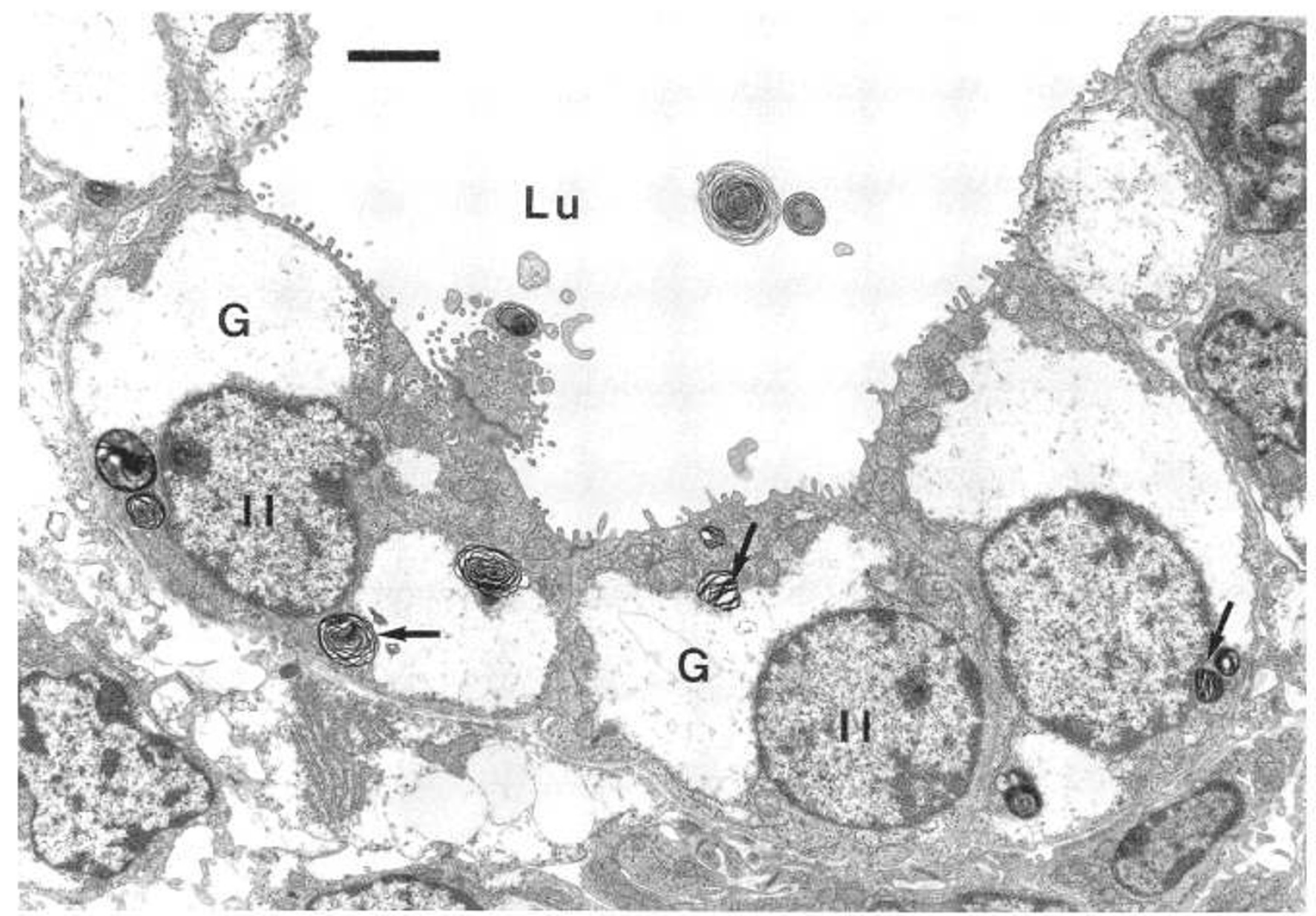

Fig. 2. Electron micrograph of respiratory epithelium from gestational day $19(\mathrm{bar}, 2.0 \mu \mathrm{m})$. Note more cuboidal-shaped epithelial cells, some of which now can be identified as type II cells $(I I)$ by the presence of lamellar bodies (arrow). Note also the large accumulations of intracellular glycogen $(G)$ in these early type II cells and the lamellar whorls in the airway lumen $(L u)$. These characteristics are typical of the canalicular stage of lung development.

Lung SP-A content. SP-A content in developing fetal rat lungs is shown in Figure 4. SP-A was undetectable by ELISA in fetal lung on $\mathrm{d} 17$ of gestation, then was barely detectable in fetal lung on d 18 of gestation. On d 19 of gestation there was a 3- to 4fold increase above d 18 levels in SP-A content, although this was not statistically significant. From gestational d 19 until 21, SP-A content significantly increased another 6- to 9-fold $(p<$ 0.05 ). Increases in SP-A content during fetal maturation occurred whether SP-A was normalized to lung DNA or lung protein. Fetal SP-A content directly correlated with mean fetal weight $\left(r^{2}\right.$ $=0.89$ ). There were no statistically significant sex differences in SP-A content for any gestational age examined.

SP-A content on the day of birth was not significantly different from SP-A content on gestational d 21 (Fig. 4). However, there was a significant decline in SP-A content when normalized to lung protein on postnatal d 2, 5, 7, and 14 when compared to SP-A content on gestational d 21 (Fig. $4 B)(p<0.05)$. When SP-A content was normalized to lung DNA, there was a significant $(p<0.05)$ decline only on postnatal $\mathrm{d} 7$ when compared to gestational d 21 (Fig. $4 A$ ). Between postnatal d 14 and 28 there was a significant $(p<0.05) 2$-fold increase in SP-A content. There was an additional 1.4-fold rise in SP-A content between postnatal d 28 and adulthood $(p<0.05)$. Postnatal wt did not correlate with postnatal SP-A content. There were no statistically significant sex differences in lung SP-A content for any postnatal age examined.

Lung $S P-A, S P-B$, and SP-C $m R N A$. Expression of mRNA's for SP-A, SP-B, and SP-C in fetal rat lung are shown in Figures 5-7. These Northern blots were intentionally overexposed to detect the earliest onset of fetal expression of the specific mRNA.
Consistent with recently reported results (33), two species of SP-A mRNA were detected in the fetal rat lung during late gestation (Fig. 5). Expression of the 1.6- and $0.9-\mathrm{kb}$ species of SP-A mRNA was first detected in fetal lung on gestational d 18 and then the relative abundances of these two species increased proportionately until gestational $\mathrm{d} 21$, but remained below adult levels. Expression of SP-B mRNA, as a 1.5-kb species, was also first detected in fetal lung on gestational d 18 and then increased in relative abundance to adult levels by gestational d 20 (Fig. 6). Expression of SP-C mRNA, as a $0.8-\mathrm{kb}$ species, was clearly detected in fetal lung on gestational d 17 and then increased in relative abundance to adult levels by gestational d 20-21 (Fig. 7). In the Northern blots shown (Figs. 5-7) no obvious sex differences were observed in the fetal expression of any of the apoprotein mRNA on d 17-18 of gestation. As noted above, these autoradiograms were intentionally overexposed to detect the earliest onset of expression, thus resulting in overexposing of the samples of later gestational ages. Shortening the exposure time on these blots, however, revealed that there were also no obvious sex differences on days 19-21 (data not shown). Shortening of exposure times also better demonstrated the comparison of relative abundance of the three apoprotein mRNA between late gestation fetuses and adult animals. Control preparations of RNA extracted from rat liver and kidney showed no hybridization with any of the cDNA probes used (Figs. 5-7).

\section{DISCUSSION}

In this study, we describe the ontogeny of SP-A and SP-A mRNA in the developing rat lung. We also describe for the first 


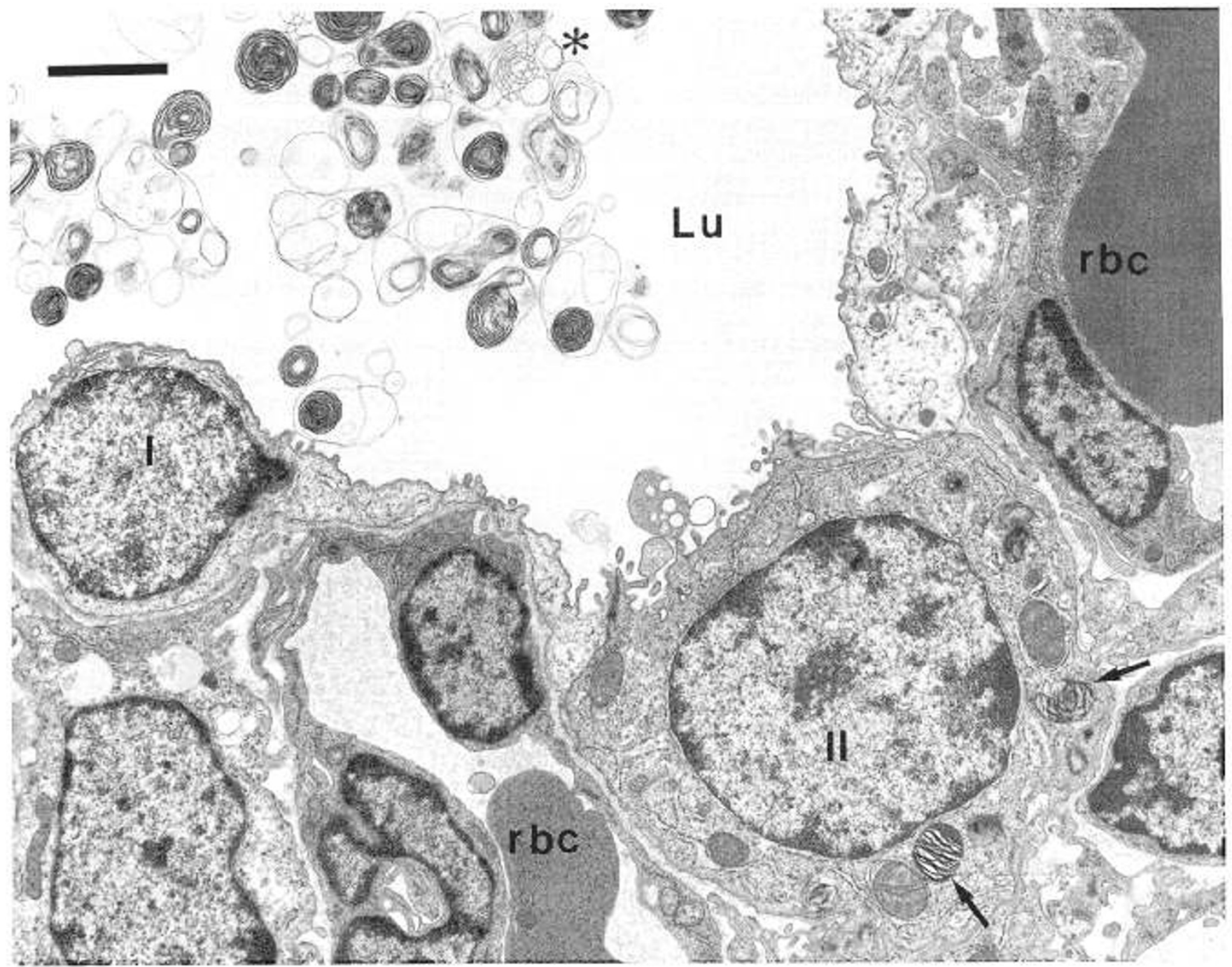

Fig. 3. Electron micrograph of respiratory epithelium from gestational d 21 (bar, $2.0 \mu \mathrm{m} ; r b c$, red blood cell). Note the mature type II cell (II) characterized by lamellar bodies (arrow) and no intracellular accumulation of glycogen. Note also the type I cell $(I)$ characterized by no lamellar bodies, attenuated cytoplasm, and close approximation to the capillary endothelium. Lamellar whorls and tubular myelin (asterisk) are present in the airway lumen $(L u)$. These characteristics are typical of the terminal sac stage of lung development.

time the expression of mRNA for the hydrophobic surfactant apoproteins, SP-B and SP-C, in the developing rat lung during late gestation. The results show that SP-A and SP-A mRNA were not detected until type II cells appeared morphologically in the lung. Then SP-A and SP-A mRNA increased in parallel until term, but never reached levels seen in the adult lung. The results also show that fetal rat SP-A mRNA is expressed as two species of mRNA $(1.6$ and $0.9 \mathrm{~kb})$ that appear to accumulate in near constant relative abundance until term. SP-B mRNA was detected as a $1.5-\mathrm{kb}$ species at the time of morphologic appearance of type II cells; however, unlike SP-A mRNA, its relative abundance increased to adult levels before the end of gestation. In contrast to SP-A mRNA and SP-B mRNA, SP-C mRNA was clearly detected as a $0.8-\mathrm{kb}$ species before the morphologic appearance of type II cells, and similar to SP-B mRNA, its relative abundance increased to adult levels before the end of gestation. We were unable to demonstrate sex differences in SP-A content or in the expression of the three surfactant apoprotein mRNA during fetal lung maturation.

We also report in this study changes in lung SP-A content during postnatal lung development. In agreement with previous results, we observed an initial decline in SP-A content during the lst wk of life (19). After this immediate neonatal period there was a gradual increase in SP-A content beginning at the end of the 2 nd wk of life, reaching adult levels after postnatal $\mathrm{d} 28$. We were unable to demonstrate sex differences in SP-A content during postnatal lung maturation.

In agreement with our results, SP-A has recently been shown to markedly increase in human amniotic fluid (15) and in fetal rat lung (16) during late gestation. Our results show developmental changes in fetal lung SP-A content closely parallel changes in fetal expression of SP-A mRNA. Our results are in agreement with previous results which show that two species of mRNA (1.6 and $0.9 \mathrm{~kb}$ ) encode adult rat SP-A (20) and that these two species of mRNA accumulate in relatively constant proportions during late gestation (33). These two species of mRNA arise from differential polyadenylation of a single primary gene transcript and encode an identical final SP-A polypeptide (33). The significance of the two species of rat SP-A mRNA awaits further elucidation.

Our results are also similar to the limited results available concerning the expression of mRNA for the hydrophobic surfactant apoproteins. Recently, the relative abundance of mRNA for the hydrophobic surfactant apoproteins has been shown to increase in human fetal lung from 16 to $24 \mathrm{wk}$ gestation (34). Furthermore, the same investigators showed that the relative abundance of both SP-B mRNA and SP-C mRNA increased rapidly in explant culture of human fetal lung, but the time sequence of this increase differed from changes in the relative abundance of SP-A mRNA, which increased somewhat later 

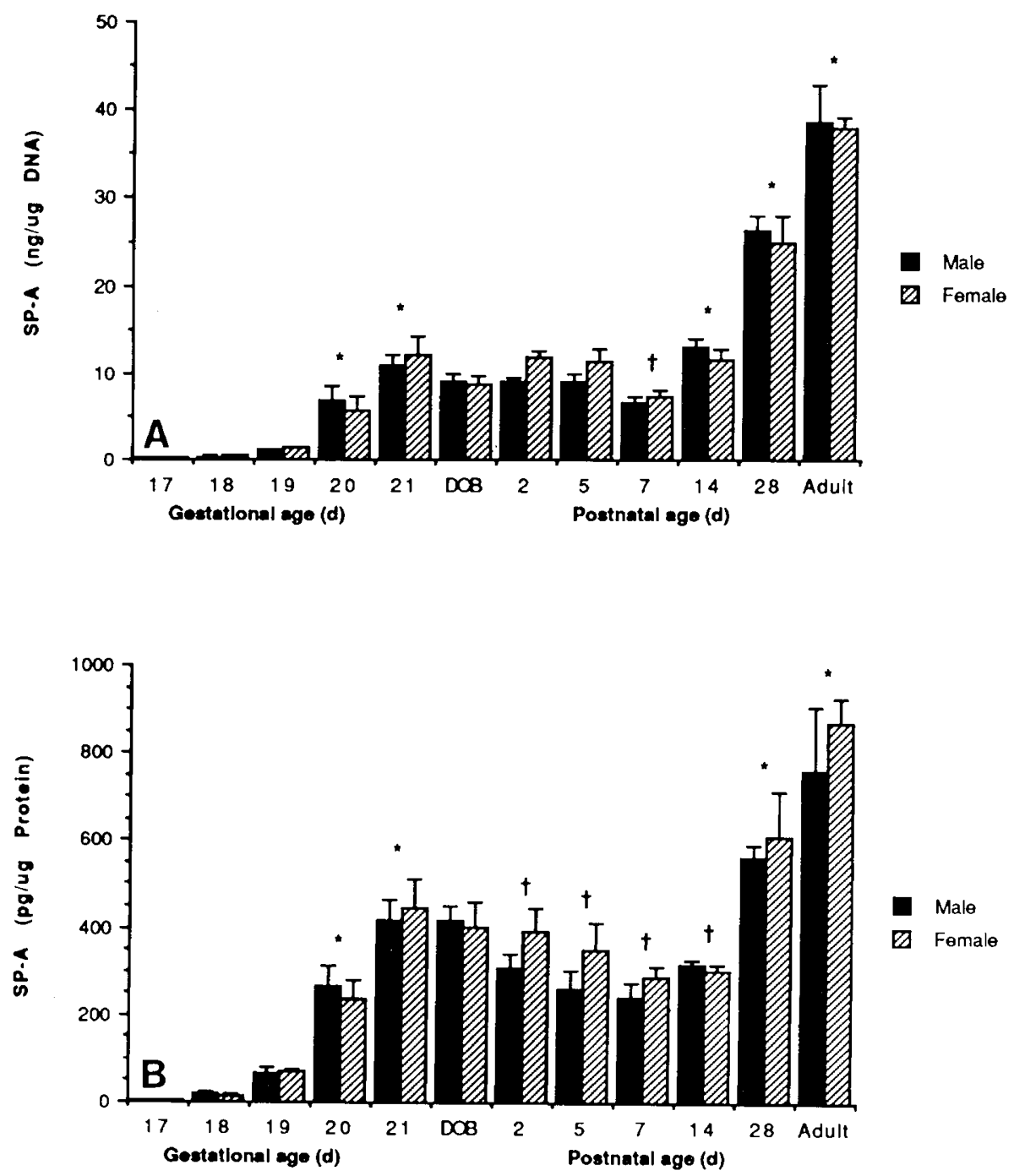

Fig. 4. Ontogeny of lung SP-A (ng/ $\mu \mathrm{g}$ DNA) in the rat. During fetal lung maturation, SP-A content was detected as early as $d 18$ and then rapidly decreased to $\mathrm{d} 21$. During postnatal lung development, SP-A content remained unchanged during the first $5 \mathrm{~d}$ of life, declined by $39 \%$ on $\mathrm{d} 7$ (when compared to gestational d 21), and then gradually increased, reaching adult levels after d 28. There were no significant sex differences in SP-A content for any age examined. Values expressed as mean \pm SE. * Lung SP-A content significantly different from SP-A content on the previous gestational or postnatal day $(p<0.05)$. †Lung SP-A content significantly different from SP-A content on gestational d $21(p<0.05)$. $B$, Ontogeny of lung SP-A (pg/ $\mu$ g protein) in the rat. During fetal lung maturation, SP-A content was detected as early as $d 18$ and then rapidly increased to d 21 . During postnatal lung development, SP-A content remained unchanged between gestational d 21 and the day of birth, declined during the 1 st wk of life (nadir postnatal d 7,39\% decrease), and then gradually increased, reaching adult levels after $\mathrm{d} 28$. There were no significant sex differences in SP-A content for any age examined. Values expressed as mean \pm SE. ${ }^{*}$ Lung SP-A content significantly different from SP-A content on the previous gestational or postnatal day $(p<0.05)$. $\dagger$ Lung SP-A content significantly different from SP-A content on gestational day $21(p<0.05)$.

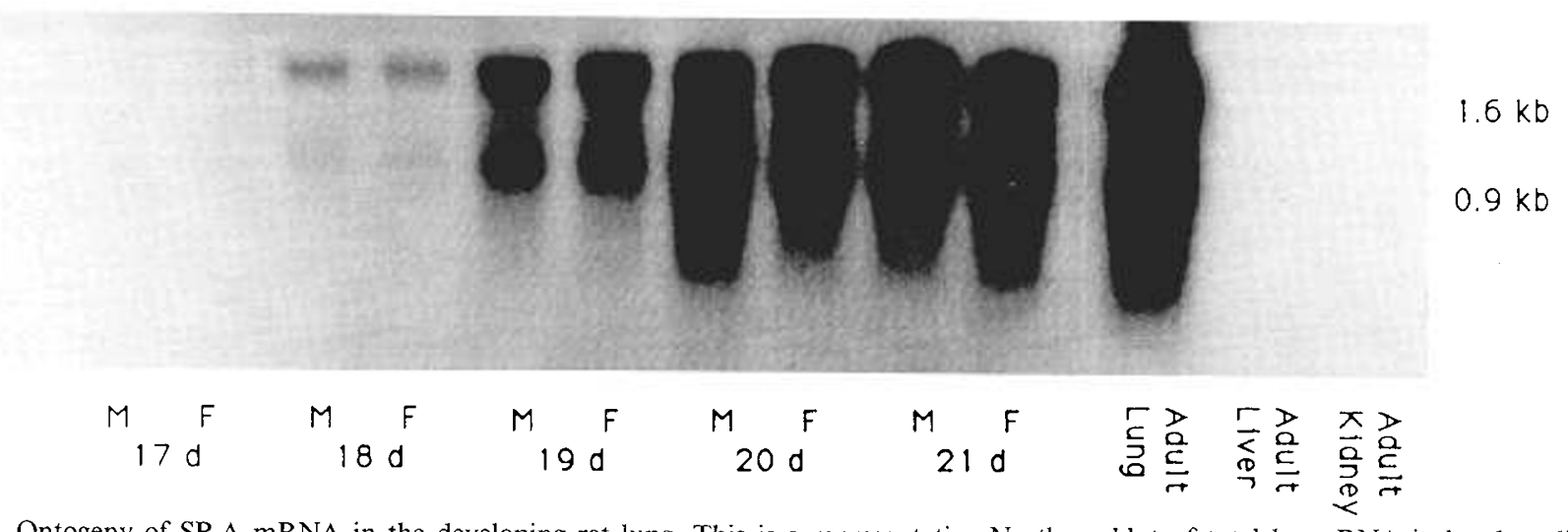

Fig. 5. Ontogeny of SP-A mRNA in the developing rat lung. This is a representative Northern blot of total lung RNA isolated at different gestational ages from pooled fetal lung, fractionated by electrophoresis, and probed with SP-A cDNA. Each lane was loaded with $10 \mu \mathrm{g}$ RNA. This blot was intentionally overexposed to show that SP-A mRNA was first detected as both the 1.6- and 0.9-kb species on d 18 of gestation. The relative abundance of these two species then increased proportionally until d 21 of gestation, but remained below levels observed in adult lungs. On this and other less exposed blots, there were no consistent differences between male and female pooled lungs isolated from the same litter. SP-A mRNA was not detected in liver or kidney. 


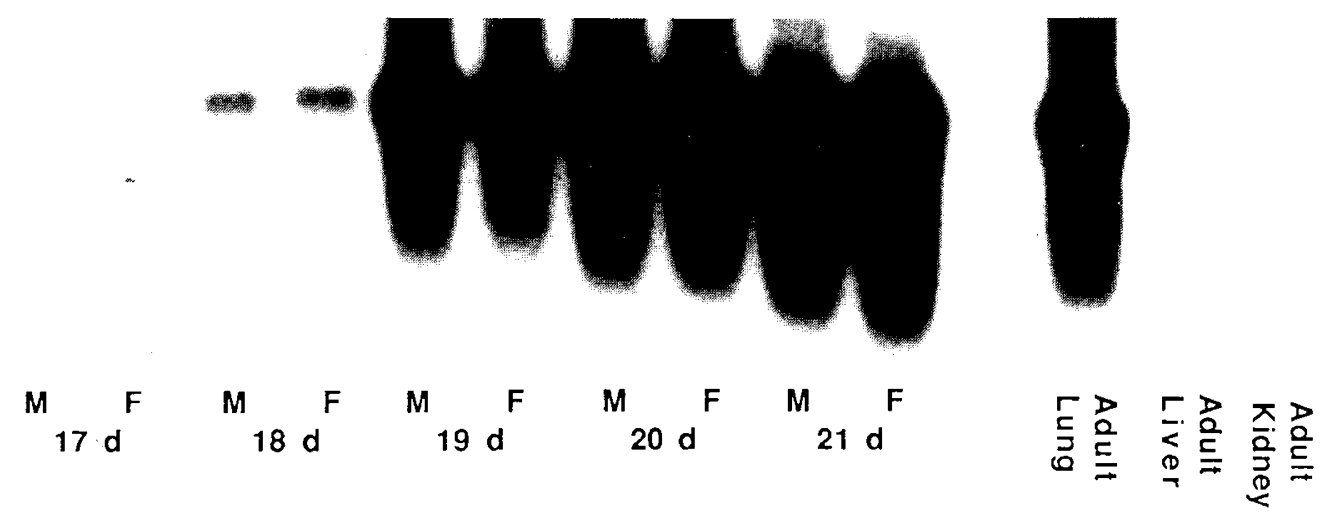

Fig. 6. Ontogeny of SP-B mRNA in the developing rat lung. This is a representative Northern blot of total lung RNA isolated at different gestational ages from pooled fetal lung and probed with SP-B cDNA. Each lane was loaded with $10 \mu \mathrm{g}$ RNA. This blot was intentionally overexposed to show that SP-B mRNA was first detected as a $1.5-\mathrm{kb}$ species on d 18 . The relative abundance of SP-B mRNA then rapidly increased to adult levels by $\mathrm{d} 20$ of gestation. On this and other less exposed blots, there were no consistent differences between male and female pooled lungs isolated from the same litter. SP-B mRNA was not detected in liver or kidney.

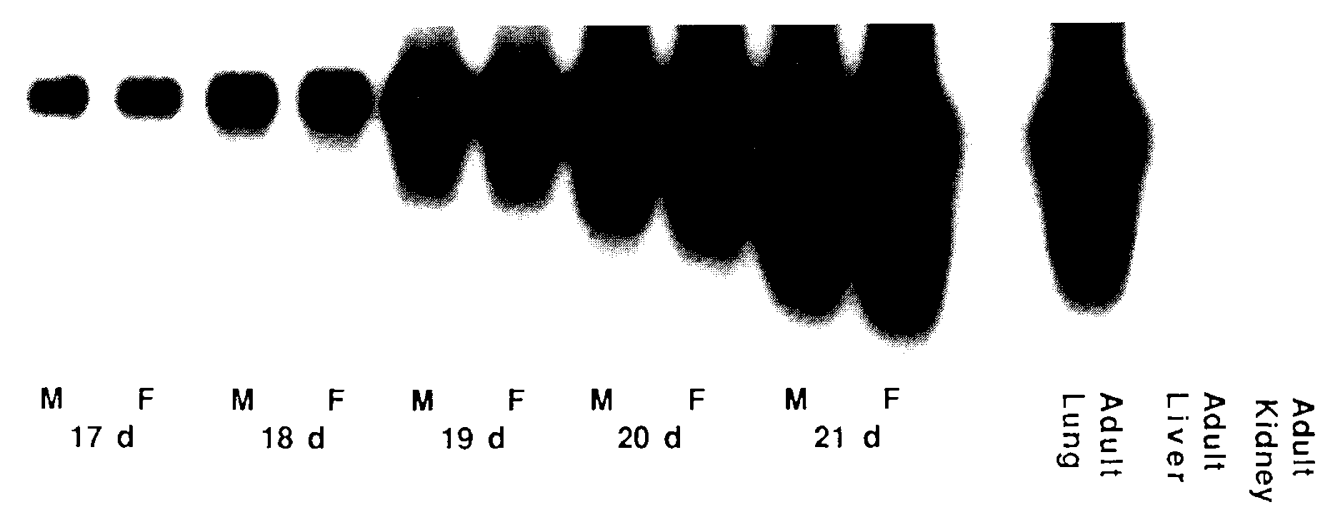

Fig. 7. Ontogeny of SP-C mRNA in the developing rat lung. This is a representative Northern blot of total lung RNA isolated at different gestational ages from pooled fetal lung and probed with SP-C cDNA. Each lane was loaded with $10 \mu \mathrm{g}$ RNA. This blot was intentionally overexposed to show that SP-C mRNA was clearly detectable as a $0.8-\mathrm{kb}$ species on $\mathrm{d} 17$. The relative abundance of SP-C mRNA then rapidly increased to adult levels by $\mathrm{d} 20-21$. On this and other less exposed blots, there were no consistent differences between male and female pooled lungs isolated from the same litter. SP-C mRNA was not detected in liver or kidney.

(34). Our results show that not only does the accumulation of SP-B and SP-C mRNA differ from that of SP-A but also the onset of expression of SP-C mRNA appears to precede that of SP-A and SP-B. We thus speculate that the genes for the surfactant apoproteins may be differentially regulated.

The reasons for the differences in expression of the surfactant apoproteins during fetal lung maturation are unclear. The functional importance of these apoproteins, especially SP-B, in enhancing adsorption of surface-active phospholipids to an airliquid interface has recently been described $(11,39,40)$. Previous investigations have shown that the surface activity of surfactant reaches near adult levels during late gestation $(35,36)$. Our results show that the expression of mRNA for SP-B and SP-C are at adult levels during late gestation. These results correlate with observations from a number of investigators $(11,37-40)$ that SP-B and SP-C may be more functionally important proteins to the biophysical properties of surfactant than SP-A. Thus SP-B and SP-C may be better indices of lung maturation than SP-A.

Sex differences in the appearance of surfactant apoproteins in the developing fetal lung have not previously been investigated. An apparent female advantage in the developing fetal rat lung has been observed in lung epithelial cell proliferation (41), in the proportion of epithelial cells containing lamellar inclusions during late gestation, and in the appearance of surfactant phospholipids (14). A female advantage has also been observed in the appearance of surfactant phospholipids in human amniotic fluid (13) and in the incidence of respiratory distress syndrome in human premature infants after antenatal steroids (42). One pos- sibility for the lack of sex differences in the fetal expression of surfactant apoproteins observed in our study is that Northern blots are not sensitive enough to detect small changes in relative abundance of specific mRNA. However, using a sensitive ELISA, sex differences were also not detected in the fetal lung content of SP-A. Thus, on the basis of the observations in our study, the apparent female advantage in rat lung maturation during late gestation cannot be explained on the basis of sex differences in the expression of mRNA for surfactant apoproteins or in lung content of SP-A. The use of more accurate techniques to quantitate mRNA abundance may eventually show sex differences in the fetal expression of mRNA for the surfactant apoproteins. One such technique is RNA-RNA hybridization in solution (43), which can easily detect differences of less than $10 \%$ in specific mRNA copy number per cell. Further, the development of ELISA techniques to quantitate the lung content of SP-B and SP-C may eventually show sex differences in the fetal appearance and accumulation of these hydrophobic apoproteins.

In addition to the changes during fetal rat lung maturation in surfactant apoproteins reported in our study, we report the changes in content of SP-A during rat postnatal lung maturation. The reasons for the initial decline in SP-A content during the 1st wk of life are unclear. Postnatal rat lung development has been characterized by three phases (44). During $d 1$ to 4 there is "lung expansion" with only small increases in total number of lung cells. During $\mathrm{d} 4$ to approximately 13 there is "tissue proliferation" with significant increases in number of lung cells and alveoli. After day 13 there is "equilibrated growth" with slow 
increases in total number of lung cells, lung volume, and number of alveoli. The lung cell population changes significantly during the second phase (45). There is a nearly 3-fold increase in fibroblasts, 2 -fold increase in endothelial cells, and beginning on d 7 a 2-fold increase in type II cells. In addition, there is a significant increase in the number of alveoli and alveolar surface area. We speculate that the observed initial decline in SP-A content during the $1 \mathrm{st} \mathrm{wk}$ of life may be due to the rapid proliferation of fibroblasts and endothelial cells, with little change in the number of type II cells. In this case, the DNA and protein contributed by nontype II cells would effectively decrease the amount of SP-A normalized on either a DNA or protein basis. Thus it may also be true that the observed increase in SP.A content beginning at the end of the 2 nd postnatal wk may be related to the concurrent increase in number of type II cells and increasing number of alveoli. Changes in the rate of synthesis of SP-A by existing and new type II cells could present an alternative explanation for the changes we observed in SP-A content during postnatal lung maturation.

In summary, we have described the ontogeny of the surfactant apoproteins during fetal rat lung maturation and the ontogeny of SP-A during postnatal rat lung development. We have observed no sex differences in the fetal expression or appearance of surfactant apoproteins, or in postnatal changes in SP-A content. We speculate that the genes for the surfactant apoproteins may be differentially regulated, that the hydrophobic apoproteins SP-B and SP-C have an important effect on the increasing surface activity of surfactant during late gestation, and that the postnatal changes in SP-A content are related to changes in numbers and types of lung cells. A further understanding of the functional importance and regulation of the surfactant apoproteins during fetal and postnatal lung maturation may lead to additional strategies to prevent or treat infant respiratory distress syndrome and other neonatal lung disorders.

Acknowledgements. The authors appreciate the laboratory assistance of Susan D. Jennings and Michael F. Rock, and the statistical assistance of John F. LaBrecque, Ph.D.

\section{REFERENCES}

1. Mason RJ 1987 Surfactant synthesis, secretion, and function in alveoli and small airways. Respir 51(suppl 1):3-9

2. Rooney SA 1985 The surfactant system and lung phospholipid biochemistry. Am Rev Respir Dis 131:439-460

3. King RJ 1982 Pulmonary surfactant. J Appl Physiol 53:1-8

4. Possmayer F 1988 A proposed nomenclature for pulmonary surfactant-associated proteins. Am Rev Respir Dis 138:990-998

5. Wright JR, Clements JA 1987 Metabolism and turnover of lung surfactant. Am Rev Respir Dis 135:426-444

6. Benson BJ, Williams MC, Hawgood S, Sargeant T 1984 Role of lung surfactantspecific proteins in surfactant structure and function. Prog Respir Res 18:8392

7. King RJ, Macbeth MC 1979 Physicochemical properties of dipalmitoyl phosphatidylcholine after interaction with an apolipoprotein of pulmonary surfactant. Biochim Biophys Acta 557:86-101

8. Dobbs LG, Wright JR, Hawgood S, Gonzalez R, Venstrom K, Nellenbogen J 1987 Pulmonary surfactant and its components inhibit secretion of phosphatidylcholine from cultured rat alveolar type II cells. Proc Natl Acad Sci USA 84:1010-1014

9. Rice WR, Ross GF, Singleton FM, Dingle S, Whitsett JA 1987 Surfactantassociated protein inhibits phospholipid secretion from type II cells. J Appl Physiol 63:692-698

10. Kuroki Y, Mason RJ, Voelker DR 1988 Pulmonary surfactant apoprotein A structure and modulation of surfactant secretion by rat alveolar type II cells. J Biol Chem 263:3388-3394

11. Hawgood S, Benson BJ, Schilling J, Damm D, Clements JA, White RT 1987 Nucleotide and amino acid sequences of pulmonary surfactant protein SP 18 and evidence for cooperation between SP 18 and 28-36 in surfactant lipid adsorption. Proc Natl Acad Sci USA 84:66-70

12. Kresch MJ, Gross I 1987 The biochemistry of fetal lung development. Clin Perinatol 14:481-506

13. Torday JS, Nielsen HC 1987 The sex difference in fetal lung surfactant production. Exp Lung Res 12:1-19

14. Adamson IYR, King GM 1984 Sex-related differences in cellular composition and surfactant synthesis of developing fetal rat lungs. Am Rev Respir Dis 129:130-134

15. Kuroki Y, Takahashi H, Fukada Y, Mikawa M, Inagawa A, Fujimoto S, Akino
T 1985 Two-site "simultaneous" immunoassay with monoclonal antibodies for the determination of surfactant apoproteins in human amniotic fluid. Pediatr Res 19:1017-1020

16. Katyal SL, Singh G 1983 An enzyme-linked immunoassay of surfactant apoproteins. Its application to the study of fetal lung development in the rat. Pediatr Res 17:439-443

17. Mendelson CR, Chen C, Boggaram V, Zacharias C, Snyder J 1988 Regulation of the synthesis of the major surfactant apoprotein in fetal rabbit lung tissue. J Biol Chem 261:9938-9943

18. Boggaram V, Qing K, Mendelson CM 1988 The major apoprotein of rabbit pulmonary surfactant. Elucidation of primary sequence and cyclic AMP and developmental regulation. J Biol Chem 263:2939-2947

19. Phelps DS, Church S, Kourembanas S, Taeusch HW, Floros J 1987 Increases in the $35 \mathrm{kDa}$ surfactant-associated protein and its mRNA following in vivo dexamethasone treatment of fetal and neonatal rats. Electrophoresis 8.235 238

20. Setaro F, Morley CG 1976 A modified fluorometric method for the determination of microgram quantities of DNA from cell or tissue cultures. Ana Biochem 71:313-317

21. Smith PK, Krohn RI, Hermanson GT, Mallia AK, Gartner FH, Provenzan MD, Fujimoto EK, Goeke NM, Olson BJ, Klenk DC 1985 Measurement of protein using bicinchoninic acid. Anal Biochem 150:76-85

22. Chirgwin JM, Przybyla AE, MacDonald RJ, Rutter WJ 1979 Isolation of biologically active ribonucleic acid from sources enriched in ribonuclease. Biochemistry 18:5294-5299

23. Sano K, Fisher J, Mason RJ, Kuroki Y, Schilling J, Benson B, Voelker D 1987 Isolation and sequence of a cDNA clone for the rat pulmonary surfactant associated protein (PSP-A). Biochem Biophys Res Commun 144:367-374

24. Emrie PA, Shannon JM, Mason RJ, Fisher JH 1989 cDNA and deduced amino acid sequence for the rat hydrophobic pulmonary surfactant associated protein SP-B. Biochem Biophys Acta 994:215-221

25. Feinberg AP, Vogelstein B 1983 A technique for radiolabeling DNA restriction endonuclease fragments to high specific activity. Anal Biochem 132:6-13

26. Fisher JH, Shannon JM, Hoffman T, Mason RJ 1989 Nucleotide and deduced amino acid sequence of the hydrophobic surfactant protein SP-C from the rat: expression in alveolar type II cells and homology with SP-C from other species. Biochem Biophys Acta 995:225-230

27. Davis LG, Dibner MD, Battey JF 1986 Basic Methods in Molecular Biology. Elsevier Science Publishing Co, Inc, New York, p 78

28. Williams MC 1977 Conversion of lamellar body membranes into tubular myelin in alveoli of fetal rat lungs. J Cell Biol 72:260-277

29. Luft JH 1961 Improvements in epoxy resin embedding methods. J Biophys Biochem Cytol 9:409-414

30. Reynolds ES 1963 The use of lead citrate at high $\mathrm{pH}$ as an electron-opaque stain in electron microscopy. J Cell Biol 17:208-212

31. Gabriel KR 1978 A simple method of multiple comparisons of means. J Amer Stat Assoc 73:724-729

32. Williams MC 1977 Development of the alveolar structure of the fetal rat in late gestation. Fed Proc 36:2653-2659

33. Fisher JH, Emrie PA, Shannon J, Sano K, Hattler B, Mason RJ 1988 Rat pulmonary surfactant protein $\mathrm{A}$ is expressed as two differently sized mRNA species which arise from differential polyadenylation of one transcript. Biochem Biophys Acta 950:338-345

34. Whitsett JA, Weaver TE, Clark JC, Sawtell N, Glasser SW, Korfhagen TR, Hull WM 1987 Glucocorticoid enhances surfactant proteolipid Phe and pVal synthesis and RNA in fetal lung. J Biol Chem 262:15618-15623

35. Gluck L, Motoyama EK, Smits HL, Kulovich MV 1967 The biochemical development of surface activity in mammalian lung. Pediatr Res 1:237-246

36. Brumley GW, Chernick V, Hodson WA, Normand C, Fenner A, Avery ME 1967 Correlations of mechanical stability, morphology, pulmonary surfactant, and phospholipid content in the developing lamb lung. J Clin Invest 46:863-873

37. Yu SH, Wallace D, Bhavnani B, Enhorning G, Harding PG, Possmayer F 1988 Effect of reconstituted pulmonary surfactant containing the 6000 dalton hydrophobic protein on lung compliance of prematurely-delivered rabbit fetuses. Pediatr Res 23:23-30

38. Smith GB, Taeusch HW, Phelps DS, Keough KM 1988 Mixtures of low molecular weight surfactant proteins and dipalmitoyl phosphatidylcholine duplicate effects of pulmonary surfactant in vitro and in vivo. Pediat Res 23:484-490

39. Yu SH, Possmayer F 1988 Comparative studies on the biophysical activities of the low-molecular-weight hydrophobic proteins purified from bovine pulmonary surfactant. Biochem Biophys Acta 961:337-350

40. Revak SD, Merritt TA, Degryse E, Stefani L, Courtney M, Hallman M, Cochrane CG 1988 Use of human surfactant low molecular weight apoproteins in the reconstitution of surfactant biologic activity. J Clin Invest 81:826833

41. Adamson IYR, King GM 1984 Sex differences in development of fetal rat lung 1. Autoradiographic and biochemical studies. Lab Invest 50:456-460

42. Collaborative group on antenatal steroid therapy 1981 Effect of antenatal dexamethasone administration on the prevention of respiratory distress syndrome. Am J Obstet Gynecol 141:276-287

43. Durnam DM, Palmiter RD 1983 A practical approach for quantitating specific mRNAs by solution hybridization. Anal Biochem 131:385-393

44. Thurlbeck W 1975 Postnatal growth and development of the lung. Am Rev Respir Dis 111:803-844

45. Burri PH, Weibel ER 1977 Development of the Lung. Marcel Dekker, New York, pp 215-268 